\title{
Hepatic metabolism of propionate relative to meals for cows in the postpartum period
}

\author{
Katherine M. Kennedy and Michael S. Allen* \\ Department of Animal Science, Michigan State University, East Lansing 48824
}

\begin{abstract}
The objective of this research was to identify potential short-term metabolic bottlenecks of propionate metabolism in the liver of dairy cows in the postpartum (PP) period and how such bottlenecks are affected by feeding status. Propionate, produced primarily from the fermentation of starch, decreases dry matter intake for cows in the postpartum period, likely by stimulating oxidation of acetyl-CoA in the liver. In this study, 8 dairy cows $[2$ blocks of 4 cows each, $6.63 \pm 1.19$ (mean $\pm \mathrm{SD}$ ) days PP; body condition score of 2.84 $\pm 0.39]$ were administered a pulse dose of either 1.5 $\mathrm{mol} / 500 \mathrm{~mL}$ of propionic acid (PA) or $500 \mathrm{~mL}$ of water (control; CON) to the rumen either $1 \mathrm{~h}$ before or $2 \mathrm{~h}$ after feeding in a $4 \times 4$ Latin square design with a 2 $\times 2$ factorial arrangement of treatments. Liver tissue was sampled at $-1,10$ and 20 min relative to dosing, and blood was sampled at $-30,-20,-10,-1,5$, $10,15,20,25,30$, and 60 min relative to dosing. We hypothesized that rapid propionate absorption results in bottlenecks as enzymes become saturated and cofactors require regeneration. The PA treatment increased plasma propionate and insulin concentrations rapidly, with peaks reached by 5 min regardless of feeding status and cleared from the plasma within 30 min of dosing. The PA treatment decreased plasma nonesterified fatty acid concentration over 30 min compared with CON before but not after feeding. The PA treatment decreased plasma $\beta$-hydroxybutyrate concentration and increased plasma lactate concentration compared with CON both before and after feeding. The PA treatment also increased hepatic pyruvate and lactate concentrations compared with CON. The PA treatment tended to increase hepatic isocitrate and fumarate concentrations but did not affect hepatic malate and oxaloacetate concentrations, suggesting that elevated mitochondrial $\mathrm{NADH} / \mathrm{NAD}^{+}$may have slowed the isocitrate dehydrogenase and fumarase reactions. The PA treatment
\end{abstract}

Received October 26, 2018.

Accepted April 30, 2019.

*Corresponding author: allenm@msu.edu also increased succinate concentration compared with CON, suggesting that a bottleneck may be present at succinate dehydrogenase. The PA treatment tended to increase citrate concentration despite having no effects on acetyl-CoA or oxaloacetate concentrations. These results are in agreement with our hypothesis that rapid absorption of propionate from the rumen and extraction by the liver results in metabolic bottlenecks in the liver that may affect feeding behavior and dry matter intake in dairy cows in the PP period.

Key words: hepatic oxidation, liver, propionate, dairy cow

\section{INTRODUCTION}

Dairy cows in the immediate postpartum (PP) period are in a negative energy balance as energy output in milk increases rapidly and appetite is depressed. This exacerbates the pre-existing lipolytic state, increasing the risk for metabolic disorders that can lead to decreased milk yield, feed conversion efficiency, and ultimately, fertility. According to the hepatic oxidation theory (HOT; Allen et al., 2009), oxidation of fuels in the liver can stimulate satiety by transmitting signals via hepatic vagal afferents to feeding centers in the brain. During meals, tricarboxylic acid (TCA) cycle intermediates increase, stimulating the oxidation of acetyl coenzyme A (CoA) in the TCA cycle. Oxidation of fuels and production of ATP over minutes can vary greatly, likely affecting feeding behavior (Allen et al., 2009).

Hypophagic effects of propionate have been documented extensively among ruminants (Allen, 2000); however, these anaplerotic effects are dependent upon the availability of acetyl-CoA to be oxidized (Allen, 2014). A rapid ruminal infusion rate of propionic acid in dairy cows in the PP period delayed satiety compared with a slower rate of infusion, possibly resulting from metabolic bottlenecks as enzymes become saturated and cofactors require regeneration (Maldini and Allen, 2018). Additionally, a pilot study performed in our laboratory (Kennedy and Allen, 2017) identified potential short-term hepatic metabolic bottlenecks-points 
at which metabolism may be impeded - of propionate metabolism, including malate dehydrogenase (EC 1.1.1.37), methylmalonyl-CoA mutase (EC 5.4.99.2), and succinyl-CoA synthetase (EC 6.2.1.4).

Although much research has been conducted to determine the metabolic effects of propionate on liver metabolism, most of these studies used cells from bovine calves or were conducted over a period of hours, or both (Aiello et al., 1989; Donkin and Armentano, 1995; Zhang et al., 2015). No research has examined the short-term effects of propionate over a time scale of minutes, with particular focus on its relation to the stimulation of oxidation in the TCA cycle and how it may relate to feeding behavior in mature dairy cows. Ruminal absorption and liver metabolism of propionate before and after meals has not been quantified in a short-term time scale and may vary greatly, affecting feeding behavior in accordance with the HOT (Allen et al., 2009). The objective of this research was to identify potential short-term metabolic bottlenecks of propionate metabolism in the liver in dairy cows in the PP period and how they are affected by feeding status. We hypothesized that rapid propionate absorption results in metabolic bottlenecks and that these bottlenecks are greater after feeding due to partial saturation of the propionate metabolism pathway from diet-derived propionate.

\section{MATERIALS AND METHODS}

The Institutional Animal Care and Use Committee at Michigan State University approved all experimental procedures for this experiment.

\section{Animals, Housing, and Diets}

Eight Holstein cows (4 primiparous and 4 multiparous) were used in this experiment. Cows were housed in individual tiestalls for the duration of the experiment and milked twice daily in the milking parlor. Cows were fed a TMR once daily at $110 \%$ of expected intake at $0800 \mathrm{~h}$, and received a common experimental diet from parturition throughout the experiment. The experimental diet (Table 1) was formulated to contain $28 \%$ NDF, $23 \%$ starch, and $17.4 \% \mathrm{CP}$ on a DM basis and consisted of corn silage, alfalfa silage, alfalfa hay, dry ground corn, soybean meal, soybean hulls, and a premix of protein supplement, minerals, and vitamins.

\section{Experimental Design and Treatments}

The experimental design was a replicated $4 \times 4$ Latin square with a $2 \times 2$ factorial arrangement of treatments balanced for carryover effects. Animals were blocked based on parity. The primiparous animals were $6.25 \pm$ 1.50 (mean $\pm \mathrm{SD}$ ) d PP at the start of the experiment and had a BCS of $2.63 \pm 0.11$ and BW of $596 \pm 21.7$ $\mathrm{kg}$. The multiparous animals were $7.00 \pm 0.82 \mathrm{~d} \mathrm{PP}$ at the start of the experiment, with BCS of $3.06 \pm 0.36$ and $\mathrm{BW}$ of $731 \pm 39.6 \mathrm{~kg}$. Treatments consisted of a pulse dose of either $1.5 \mathrm{~mol} / 500 \mathrm{~mL}$ of propionic acid (PA; food grade, 99.5\%; Kemin Industries Inc., Des Moines, IA) or $500 \mathrm{~mL}$ of water (control, CON) into the rumen via orogastric intubation either $1 \mathrm{~h}$ before or $2 \mathrm{~h}$ after feeding (dose relative to feeding, DRF). Each block was randomly allocated to a treatment sequence in which each animal received each treatment once, and only one treatment was administered per $\mathrm{d}$ (period). Period is defined as the day that a treatment was administered $(\mathrm{n}=4)$ and consisted of all sampling conducted within that day. One primiparous cow became ill before treatment or sampling on the first day of treatment and was dropped from the study. She was replaced with another primiparous cow for the remainder of the study; however, no samples were taken from the replacement cow during the first period. A rest day was provided between periods to minimize risk of carryover effects.

\section{Data and Sample Collection}

Animals were transferred to a surgery room at the Michigan State University Dairy Cattle Teaching and Research Center (East Lansing) for the dosing of treatment, as well as liver and blood collections. Feed offered was adjusted daily for individual animals. Samples (0.5 $\mathrm{kg}$ ) of all dietary ingredients and the TMR were col-

Table 1. Ingredients and nutrient composition of experimental diet (\% of dietary DM, except for DM)

\begin{tabular}{lc}
\hline Item & $\%$ \\
\hline Ingredient & \\
Corn silage & 29.9 \\
Ground corn & 19.5 \\
Soybean meal & 16.4 \\
Alfalfa silage & 15.3 \\
Alfalfa hay & 13.6 \\
Vitamin and mineral mix $^{1}$ & 4.2 \\
Soybean hulls & 1.1 \\
Nutrient composition & 53.5 \\
DM & 90.0 \\
OM & 22.8 \\
Starch & 27.6 \\
NDF & 24.0 \\
Forage NDF & 17.4 \\
CP & \\
\hline
\end{tabular}

${ }^{1}$ Vitamin and mineral mix contained $11.4 \% \mathrm{NaCl}, 12.8 \% \mathrm{Ca}, 0.99 \%$ $\mathrm{Mg}, 0.99 \% \mathrm{P}, 10.9 \% \mathrm{Na}, 14 \mathrm{mg} / \mathrm{kg}$ of Co, $250 \mathrm{mg} / \mathrm{kg}$ of Cu, $9.9 \mathrm{mg} / \mathrm{kg}$ of I, $745 \mathrm{mg} / \mathrm{kg}$ of Fe, $994 \mathrm{mg} / \mathrm{kg}$ of Mn, $7.5 \mathrm{mg} / \mathrm{kg}$ of Se, $1,093 \mathrm{mg} /$ $\mathrm{kg}$ of $\mathrm{Zn}, 30.6 \mathrm{kIU} / \mathrm{kg}$ of vitamin A, $5.1 \mathrm{kIU} / \mathrm{kg}$ of vitamin $\mathrm{D}$, and 152 $\mathrm{IU} / \mathrm{kg}$ of vitamin $\mathrm{E}$. 
lected daily throughout the experiment and stored in plastic bags at $-20^{\circ} \mathrm{C}$ until processed.

Animals were fitted with jugular catheters $2 \mathrm{~d}$ before the start of the experiment. Catheters were maintained by flushing the lines twice daily with approximately 5 $\mathrm{mL}$ of a sterile $3.5 \%$ sodium citrate solution. Blood was collected from the jugular catheter at $-30,-20,-10$, and -1 min before dosing to determine baseline values and at 5, 10, 15, 20, 25, 30, and 60 min after dosing. Blood samples were collected into 3 tubes containing $\mathrm{K}_{2}$ EDTA and 1 tube containing potassium oxalate with $\mathrm{NaF}$ as a glycolytic inhibitor (Vacutainer tubes; VWR International, Radnor, PA), and placed on ice until centrifugation. Tubes were centrifuged at $1,700 \times g$ for 15 min at $4^{\circ} \mathrm{C}$ immediately after sample collection. Plasma was harvested and frozen at $-20^{\circ} \mathrm{C}$ until analysis.

Liver samples (approximately 300 to $400 \mathrm{mg}$ ) were biopsied at $-1,10$, and 20 min relative to dosing. Liver biopsies were performed as modified from Bradford and Allen (2005). Briefly, the liver was accessed on the right side of the cow at the 10th intercostal space between the 11th and 12th ribs, located approximately $5 \mathrm{~cm}$ above the line between the olecranon and the tuber coxae. The area for the biopsy was clipped and cleaned using gauze soaked in $7.5 \%$ povidone-iodine, followed by gauze soaked in $70 \%$ ethanol. The biopsy site was locally anesthetized with up to $40 \mathrm{~mL}$ of $2 \%$ lidocaine hydrochloride as deemed necessary to maximize cow comfort during the procedure. Lidocaine was injected directly to the biopsy site and intramuscularly on the surrounding area. To ensure that the liver was in the expected location, a sterile biopsy needle (14-gauge, Wilburn Medical USA, Kernersville, NC) was used to take an initial biopsy sample. Upon confirmation of liver tissue, liver was biopsied using a stainless steel biopsy needle of $0.4 \mathrm{~cm}$ outer diameter. Samples were flash frozen in liquid nitrogen, stored on dry ice for transportation, and then stored at $-80^{\circ} \mathrm{C}$ until further analysis.

\section{Analysis of Samples}

Feed Ingredients. Feed ingredient samples were composited and dried in a $55^{\circ} \mathrm{C}$ forced-air oven for 72 $\mathrm{h}$, ground with a Wiley mill (1-mm screen; Thomas Scientific, Swedesboro, NJ), and analyzed for DM, ash, NDF, starch, and $\mathrm{CP}$ concentrations according to Gualdrón-Duarte and Allen (2017). All nutrients are expressed on a DM basis.

Plasma. Commercial kits were used to determine concentrations of nonesterified fatty acids (NEFA; NEFA HR kit; Wako Chemicals USA, Richmond, VA) and BHB (kit no. 2240; Stanbio Laboratory, Boerne, TX). Glucose was determined using a glucose oxidase method (Sigma Aldrich, St. Louis, MO). The above metabolites were analyzed colorimetrically with a microplate reader (SpectraMax Plus 384; Molecular Devices, San Jose, CA) to determine the plasma concentrations of metabolites. Insulin concentration was determined using a bovine insulin ELISA kit (kit no. 10-1201-01; Mercodia, Uppsala, Sweden). Plasma propionate concentrations were analyzed by HPLC as described by Gualdrón-Duarte and Allen (2017). Plasma acetate and lactate were analyzed by HPLC, and samples were prepared in the same manner as plasma propionate, as described by Gualdrón-Duarte and Allen (2017). Baseline plasma concentrations for each factor were determined using samples collected before dosing.

Liver Sample Preparation. Liver samples were analyzed for citrate, isocitrate, succinate, fumarate, malate, pyruvate, lactate, BHB, glutamate, aspartate, oxaloacetate (OAA), $\alpha$-ketoglutarate, glucose, and $\gamma$-aminobutyric acid (GABA) by GC-MS and for CoA, acetyl-CoA, propionyl-CoA, succinyl-CoA, and methylmalonyl-CoA by liquid chromatography-tandem mass spectrometry (LC-MS/MS). Approximately $40 \mathrm{mg}$ of frozen tissue was weighed into clean, flatbottom $2-\mathrm{mL}$ centrifuge tubes stored on dry ice. Tissue weights were recorded, and results were expressed per $\mathrm{g}$ of wet weight. We added $500 \mu \mathrm{L}$ of $1 \%$ formic acid in $30 \%$ ACN: $70 \% \mathrm{H}_{2} \mathrm{O}$ stored on ice to each tube and immediately homogenized using a Polytron PT 1200E homogenizer (Kinematica, Luzern, Switzerland) for $30 \mathrm{~s}$. Samples were centrifuged at $5,000 \times g$ for 10 min at $4^{\circ} \mathrm{C}$. The supernatant was transferred to clean centrifuge tubes for analysis and stored at $-80^{\circ} \mathrm{C}$. All samples for GC-MS and LC-MS/MS were evaporated to dryness using a Savant SC110 SpeedVac Concentrator (Savant Instruments Inc., Holbrook, NY).

Gas Chromatography-Mass Spectrometry. Samples evaporated to dryness were derivatized by methoximation and trimethylsilylation as modified by Kind et al. (2009), except that $N$-tert-butyldimethylsilyl- $N$-methyltrifluoroacetamide with $1 \%$ tert-butyldimethylchlorosilane (MTBSTFA + 1\% t-BDMCS; Sigma Aldrich) or $\mathrm{N}, \mathrm{O}$-bis(trimethylsilyl)trifluoroacetamide with $1 \%$ trichloromethylsilane (BSTFA with $1 \%$ TMCS; Sigma Aldrich) was used instead of $N$-methyl$\mathrm{N}$-(trimethylsilyl)trifluoroacetamide, as noted in Table 2. Briefly, $30 \mu \mathrm{L}$ of O-methylhydroxylamine reagent solution (40 mg/1 mL of pyridine; Sigma Aldrich) was added to each sample and vortexed for $30 \mathrm{~s}$. Samples were then shaken for $3 \mathrm{~h}$ at $60^{\circ} \mathrm{C}$ in a Forma Orbital Shaker Model 420 (Thermo Fisher Scientific, Waltham, MA). An additional $90 \mu \mathrm{L}$ of either MTBSTFA or BSTFA was added to each sample, vortexed for 10 $\mathrm{s}$, and then shaken for an additional $30 \mathrm{~min}$ at $37^{\circ} \mathrm{C}$. Samples were then centrifuged for $10 \mathrm{~min}$ at $5,000 \times g$ 
Table 2. Analyte parameters measured on GC-MS; each analyte was monitored using 2 ions (A and B)

\begin{tabular}{|c|c|c|c|}
\hline Analyte & Retention time (min) & $m / z$ monitored $(\mathrm{A})$ & $m / z$ monitored $(\mathrm{B})$ \\
\hline Pyruvate $^{1}$ & 5.54 & $174.1^{2}$ & 216.1 \\
\hline Lactate $^{1}$ & 6.85 & 233.1 & $261.1^{2}$ \\
\hline 3 -Hydroxybutryrate ${ }^{1}$ & 7.53 & 159.1 & $275.1^{2}$ \\
\hline Succinate $^{1}$ & 8.76 & $289.1^{2}$ & 331.1 \\
\hline Fumarate $^{1}$ & 9.03 & $287.1^{2}$ & 329.1 \\
\hline Phosphate $^{1}$ & 10.03 & $383.2^{2}$ & 425.2 \\
\hline Malate $^{1}$ & 11.60 & 287.2 & $419.3^{2}$ \\
\hline Aspartate $^{1}$ & 11.98 & $418.3^{2}$ & 460.3 \\
\hline Glutamate $^{1}$ & 12.97 & $432.3^{2}$ & 474.3 \\
\hline Citrate $^{1}$ & 15.57 & 459.3 & $591.4^{2}$ \\
\hline Isocitrate $^{1}$ & 15.65 & 459.3 & $591.4^{2}$ \\
\hline Oxaloacetate $^{3}$ & 6.67 & 98.0 & $290.1^{2}$ \\
\hline $\mathrm{GABA}^{3,4}$ & 7.12 & $174.1^{2}$ & 304.1 \\
\hline$\alpha$-Ketoglutarate ${ }^{3}$ & 7.39 & $198.1^{2}$ & 304.1 \\
\hline Glucose $^{3}$ & 9.8 & 205.1 & $319.2^{2}$ \\
\hline
\end{tabular}

at $22^{\circ} \mathrm{C}$. The supernatant was transferred into a 250 $\mu \mathrm{L}$ glass insert within a 2-mL amber autosampler vial (Thermo Fisher Scientific). Vials were stored in a desiccator in the dark until analysis by GC-MS within $48 \mathrm{~h}$ of derivatization. Analysis of peaks was conducted with MassLynx Mass Spectrometry Software (version 4.1; Waters Corporation, Milford, MA). Peaks were identified and quantified by comparison with standards.

Analysis was performed on an Agilent Technologies 6890N Network GC system coupled to an Agilent Technologies 5975B inert XL MSD mass spectrometer. The GC features a CombiPAL autosampler, helium carrier gas, and an Agilent VF-5ms $30-\mathrm{m} \times 0.25-\mathrm{mm} \times 0.25-$ $\mu \mathrm{m}$ capillary column with an integrated 10-m EZ-Guard guard column (Agilent Technologies, Santa Clara, CA; $\mathrm{P} / \mathrm{N}$ CP9013). Method-specific parameters include an inlet temperature of $280^{\circ} \mathrm{C}$, a $10: 1$ injection split ratio, $70 \mathrm{eV}$ electron ionization, and selected ion monitoring MS analysis of the target compounds (Table 2). The oven program was as follows: initial temperature of $40^{\circ} \mathrm{C}$ and held for $1 \mathrm{~min}$, programmed at $40^{\circ} \mathrm{C} / \mathrm{min}$ to $110^{\circ} \mathrm{C}$ and held for $1 \mathrm{~min}$, then programmed at $40^{\circ} \mathrm{C} /$ min to $170^{\circ} \mathrm{C}$, then programmed at $10^{\circ} \mathrm{C} / \mathrm{min}$ to $300^{\circ} \mathrm{C}$ and held for $2.75 \mathrm{~min}$, for a total run time of $21.25 \mathrm{~min}$ per sample.

Liquid Chromatography-Tandem Mass Spectrometry. Samples evaporated to dryness were resuspended in $400 \mathrm{~m} M$ ammonium formate with $10 \mathrm{mM}$ tris(2-carboxyethyl)phosphine $\mathrm{HCl}$ (Sigma Aldrich). Samples were centrifuged twice at $5,000 \times g$ for 10 min each at $4^{\circ} \mathrm{C}$ and the supernatant aliquoted to new centrifuge tubes between bouts of centrifugation. The supernatant was then transferred into a $250-\mu \mathrm{L}$ glass insert within a 2-mL amber autosampler vial (Thermo Fisher Scientific) for analysis on LC-MS/MS. Peaks were identified and quantified by comparison with standards. Analysis of peaks was conducted with MassLynx Mass Spectrometry Software (version 4.1, Waters Corporation).

Analysis of samples was performed on an Acquity ultra-performance LC system coupled to a Quattro Premier XE triple quadrupole MS using an Acquity UPLC BEH C18 1.7 m $2.1 \times 100-m m$ column (Waters Corporation). This is a modified version of the method by Gotoh et al. (2015). The LC operation used the mobile phases: $400 \mathrm{mM}$ ammonium formate (A) and acetonitrile (B). The column oven temperature was set to $50^{\circ} \mathrm{C}$. The flow rate used on the program was set at $0.4 \mathrm{~mL} / \mathrm{min}$, with the initial parameters set at $98 \%$ mobile phase $\mathrm{A}$ and $2 \%$ mobile phase B until $4 \mathrm{~min}$. From 4 min to 6 min the gradient shifted to $50 \%$ mobile phase A and 50\% mobile phase B and held for $1 \mathrm{~min}$. At 7 min until $9 \mathrm{~min}$, the gradient shifted back to $98 \%$ mobile phase $\mathrm{A}$ and $2 \%$ mobile phase $\mathrm{B}$, for a total run time of 9 min per sample. The electrospray ionization source parameters included a source temperature of $120^{\circ} \mathrm{C}$, a gas flow of $600 \mathrm{~L} / \mathrm{h}$, a gas temperature of $350^{\circ} \mathrm{C}$, and an electron spray ionization voltage of $2.5 \mathrm{kV}$. The MS analysis was performed using multiple reaction monitoring for the target compounds; detailed information is available in Table 3 .

\section{Statistical Analysis}

Liver and plasma metabolite and hormone data were analyzed using the MIXED procedure of SAS software 
Table 3. Multiple reaction monitoring settings for coenzyme A (CoA) compounds on LC-MS/MS

\begin{tabular}{|c|c|c|c|c|c|}
\hline Analyte & Neutral mass (Da) & Precursor $m / z$ & Product $m / z$ & Cone voltage $(\mathrm{V})$ & Collusion energy (V) \\
\hline Acetyl-CoA & 809.6 & 810.1 & 303.1 & 45 & 30 \\
\hline Succinyl-CoA & 867.6 & 868.1 & 361.1 & 45 & 30 \\
\hline
\end{tabular}

(version 9.4, 2013; SAS Institute Inc., Cary, NC) as a $4 \times 4$ Latin square with a $2 \times 2$ factorial design with double repeated measures (2 factors within the model are classified as repeating). Before statistical analysis, Box-Cox transformation analyses were applied to each response variable, to determine necessary transformations on the data using JMP Pro (version 13.2, 2016; SAS Institute Inc.). All liver and plasma metabolites and hormones were analyzed using the following model:

$$
\begin{gathered}
Y_{i j k l m n}=\mu+B_{i}+C_{j}\left(B_{i}\right)+P_{k}\left(B_{i}\right)+T_{l}+S_{m}+F_{n} \\
+T_{l} S_{m}+T_{l} F_{n}+T_{l} B_{i}+F_{n} S_{m}+S_{m} P_{k}\left(B_{i}\right) \\
+T_{l} F_{n} S_{m}+e_{i j k l m n},
\end{gathered}
$$

where $Y_{i j k l m n}=$ the response variable; $\mu=$ overall mean; $B_{i}=$ fixed effect of block $i ; C_{j}\left(B_{i}\right)=$ random effect of cow $j$ nested within block $i ; P_{k}\left(B_{i}\right)=$ fixed effect of period $k$ nested within block $i$; $T_{l}=$ fixed effect of treatment $l ; S_{m}=$ fixed effect of sampling time $m ; F_{n}=$ fixed effect of dose relative to feeding $n ; T_{l} S_{m}=$ interaction of treatment and sampling time; $T_{l} F_{n}=$ interaction of treatment and dose relative to feeding; $T_{l} B_{i}=$ interaction of treatment and block; $F_{n} S_{m}=$ interaction of dose relative to feeding and sampling time; $S_{m} P_{k}\left(B_{i}\right)=$ interaction of sampling time and period nested within block; $T_{l} F_{n} S_{m}=$ interaction of treatment, dose relative to feeding, and sampling time; and $e_{i j k l m n}=$ residual. Period was treated as the macro repeated measure and sampling time as the micro repeated measure. The covariance structure was compound symmetry for all metabolites and hormones except hepatic BHB, which was first-order autoregressive due to a lower Bayesian information criterion (BIC). Denominator degrees of freedom were estimated by using the Kenward-Roger option in the MODEL statement. The covariance structure Toeplitz was also examined for plasma samples; however, compound symmetry yielded a lower BIC for all plasma metabolites and hormones. Pairwise tests were determined using the diff option in PROC MIXED for those variables that had significant interactions or tendencies for significant interactions.

Treatment effects were declared at $P \leq 0.05$, and tendencies for treatment effects were declared at $P$ $\leq 0.10$. Interactions were declared significant at $P \leq$
0.10 , and tendencies for interactions were declared at $P \leq 0.15$. Data transformed are noted in the tables and figures, along with the transformation used for statistical analysis. All transformed data has been backtransformed for interpretation purposes. Percent differences were calculated by back-transforming the least squares means from the statistical models, subtracting the baseline from the time point of interest, dividing that number by the baseline, and multiplying it by 100 .

\section{RESULTS}

\section{Plasma Metabolites and Insulin}

Treatment effects on plasma metabolites and hormones are summarized in Table 4 . Treatment interacted with sampling time to affect all plasma metabolites and hormones measured (Figure $1 ; P<0.01$ ). The PA treatment rapidly increased plasma propionate concentration, peaking at $5 \mathrm{~min}$ both before feeding $(\mathbf{B F})$ and after feeding $(\mathbf{A F})$ compared with CON, and returned to baseline within 20 and 25 min, respectively (Figure 1A; interaction, $P=0.05$ ). Plasma propionate concentration increased at a rate of 0.03 and $0.07 \mathrm{mM}$ / min $\mathrm{BF}$ and $\mathrm{AF}$, respectively, and cleared from circulation at a rate of 0.01 and $0.02 \mathrm{mM} / \mathrm{min} \mathrm{BF}$ and $\mathrm{AF}$, respectively. Additionally, the plasma propionate concentration peak was greater at $5 \min \mathrm{AF}(0.53 \mathrm{mM}$, $225 \%$ increase from baseline) than BF (0.32 $\mathrm{mM}, 109 \%$ increase from baseline) for PA (pairwise test, $P=0.05$ ). The PA treatment increased mean plasma propionate concentration compared with CON (0.20 vs. $0.15 \mathrm{mM}$; $P=0.04)$. The PA treatment increased plasma glucose concentration $\mathrm{BF}$, but not $\mathrm{AF}$, compared with $\mathrm{CON}$ (Figure 1B; $P<0.01$ ), with the peak concentration at $10 \mathrm{~min}$ after dosing. The PA treatment also increased plasma insulin concentration more $\mathrm{BF}$ than $\mathrm{AF}$ compared with CON $(P=0.09)$, with concentrations peaking at $5 \mathrm{~min}$ and returning to baseline by $30 \mathrm{~min}$ (Figure $1 \mathrm{C} ; P=0.02$ ). Plasma NEFA concentration was higher $\mathrm{BF}(1,121 \mu \mathrm{Eq})$ than $\mathrm{AF}(514 \mu \mathrm{Eq} / \mathrm{L} ; P<$ 0.01 ) and PA decreased plasma NEFA concentration to a greater extent over time BF than AF (Figure 1D; $P=0.01)$. The PA treatment decreased plasma BHB concentration over $30 \mathrm{~min}$, which remained lower at 
60 min and was lower overall for PA compared with CON (Figure 1E; $P<0.01$ ). The PA treatment reduced plasma acetate concentration compared with $\mathrm{CON}$ over time (Figure 1F; $P<0.01$ ), which was higher AF $(1.34$ $\mathrm{m} M)$ than $\mathrm{BF}(0.67 \mathrm{~m} M ; P<0.01)$. The PA treatment also interacted with time to increase plasma lactate concentration compared with CON (Figure 1G; $P<$ 0.01 ) and increased mean plasma lactate concentration compared with CON (0.50 vs. $0.38 \mathrm{mM} ; P<0.01$ ), which tended to be higher AF than BF (0.47 vs. 0.40 $\mathrm{m} M ; P=0.06)$.

\section{Liver Metabolites}

Hepatic metabolite concentrations are reported in Table 5 and Figures 2 and 3. The PA treatment tended to increase hepatic propionyl-CoA concentration over time (Figure 2A; $P=0.13$ ), with greater concentration at $10 \mathrm{~min}$ compared with $\mathrm{CON}$ (11.1 vs. $2.1 \mathrm{nmol} / \mathrm{g}$; pairwise, $P=0.02$ ) and declining to near baseline by 20 min, resulting in greater mean concentration (7.80 vs. $2.82 \mathrm{nmol} / \mathrm{g} ; P=0.04)$. Propionyl-CoA concentration was greater $\mathrm{AF}$ than $\mathrm{BF}(7.18$ vs. $3.22 \mathrm{nmol} / \mathrm{g} ; P=$ 0.05). Methylmalonyl-CoA concentration tended to be greater $\mathrm{AF}$ than $\mathrm{BF}(2.25$ vs. $1.43 \mathrm{nmol} / \mathrm{g} ; P=0.08)$ but was not affected by PA treatment.

Treatment interacted with dose relative to feeding and sampling time to affect succinyl-CoA concentration (Figure 2B; interaction, $P=0.10$ ). Relative to baseline concentration, PA did not affect succinyl-CoA concentration either $\mathrm{BF}$ or $\mathrm{AF}$ at 10 or $20 \mathrm{~min}$ (pairwise test, $P>0.10)$; however, succinyl-CoA tended to be greater for PA compared with CON AF at 20 min (26.5 vs. 8.75 $\mathrm{nmol} / \mathrm{g}$; pairwise test, $P=0.06$ ). The concentration of CoA was not affected by treatment either BF or AF.

The PA treatment increased succinate concentration compared with CON (227 vs. $163 \mathrm{nmol} / \mathrm{g} ; P=$ 0.01 ) and interacted with sampling time (Figure $2 \mathrm{C}$; $P=0.10)$. Succinate concentration was greater at 10 min for PA compared with CON (286 vs. $146 \mathrm{nmol} / \mathrm{g}$; pairwise test, $P<0.01$ ), and compared with baseline, PA increased succinate concentration $46 \%$ at $10 \mathrm{~min}$ (pairwise test, $P=0.02$ ). The $\mathrm{PA}$ treatment tended to increase mean fumarate concentration (55.0 vs. 46.9 nmol/g; $P=0.07$ ), which was greater $\mathrm{AF}$ than $\mathrm{BF}$ $(55.5$ vs. $46.5 \mathrm{nmol} / \mathrm{g} ; P=0.05)$.

Malate and OAA concentrations were not affected by treatment either BF or AF. The PA treatment increased mean citrate concentration compared with $\mathrm{CON}(P=$ $0.01)$, but the effect was detected BF (96.2 vs. 46.2 $\mathrm{nmol} / \mathrm{g}$ ) but not AF (102 vs. $81.5 \mathrm{nmol} / \mathrm{g} ; P=0.10)$. Treatments tended to interact with sampling time $(P$ $=0.12)$; PA increased citrate concentration $41 \%$ at 10 min compared with baseline (Figure 2D; pairwise test,

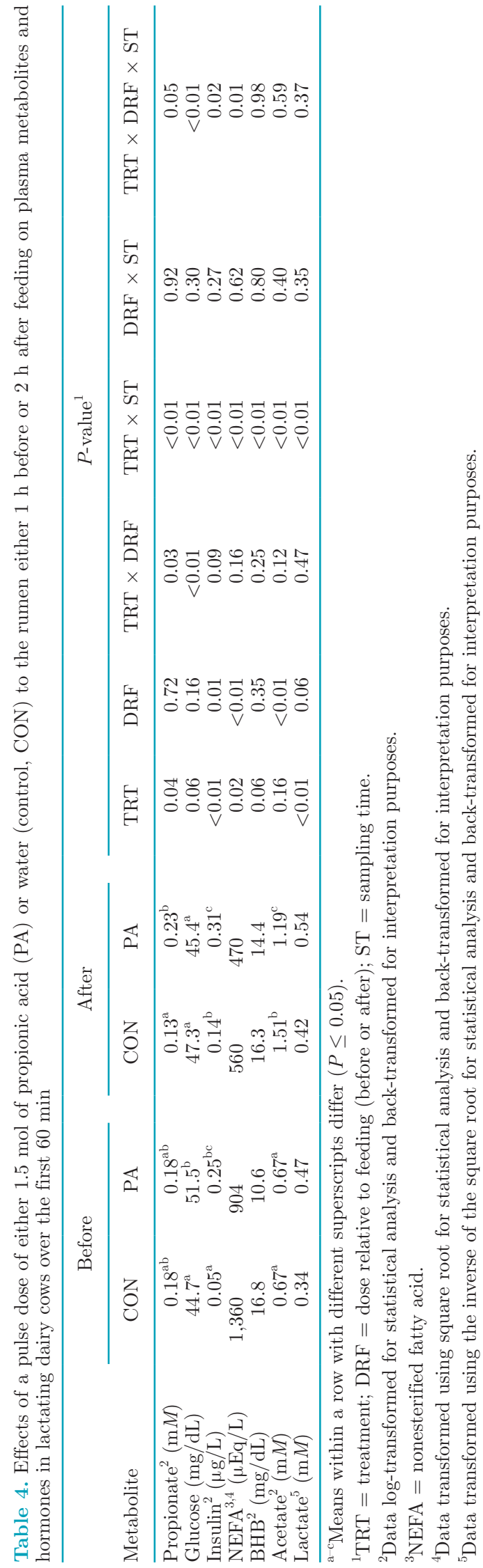


A

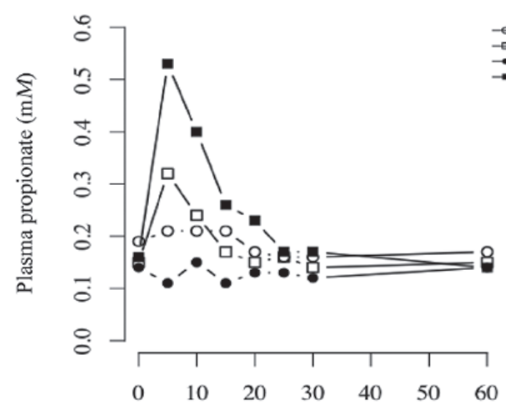

Time (min)

\section{B}

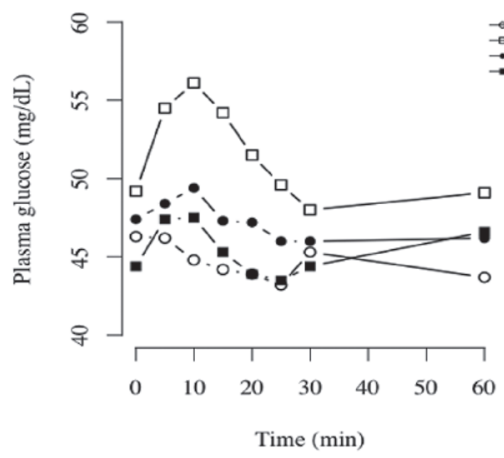

$\mathrm{C}$

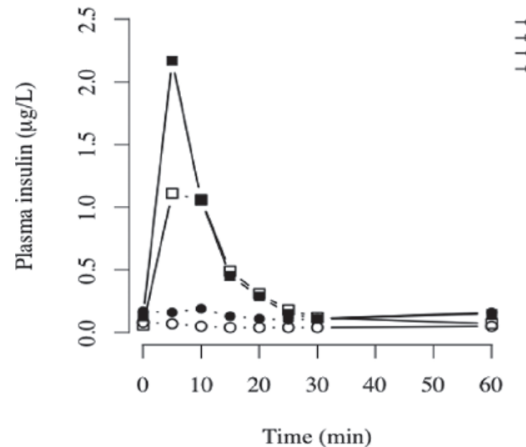

D

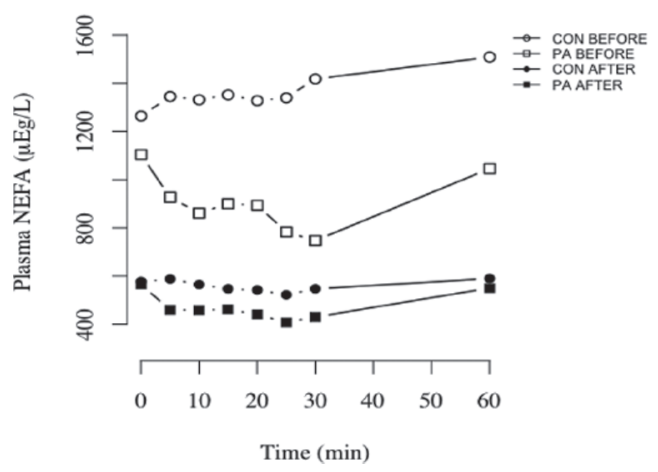

E

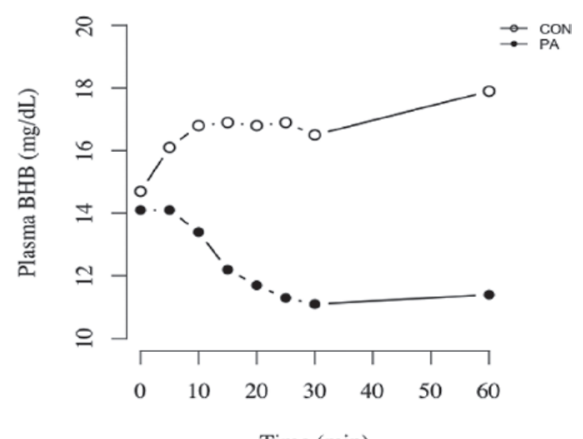

$\mathrm{F}$

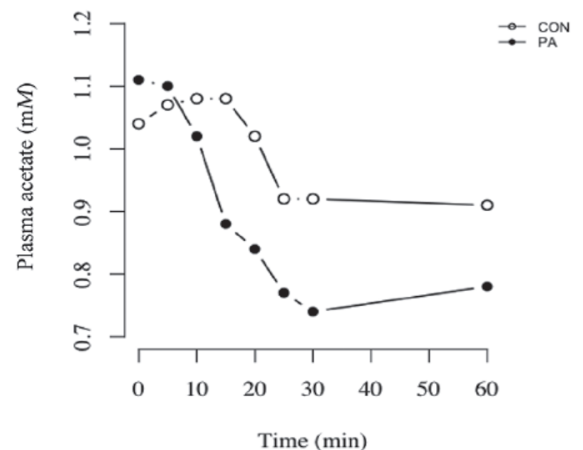

G

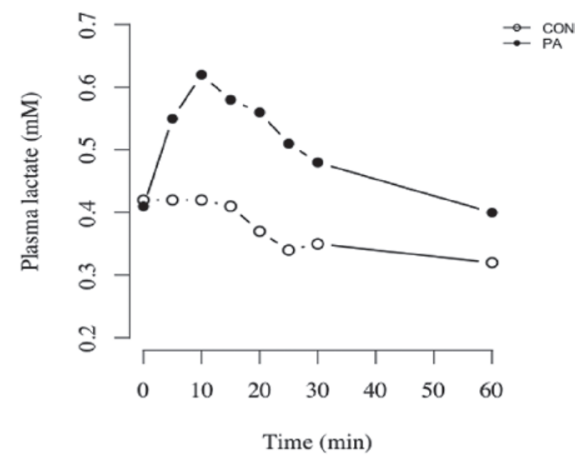

Figure 1. Effects of a pulse dose of either $1.5 \mathrm{~mol}$ of propionic acid (PA) or water (CON) to the rumen on (A) plasma propionate, (B) glucose, (C) insulin, (D) nonesterified fatty acid (NEFA), (E) BHB, (F) acetate, and (G) lactate in dairy cows in the postpartum period over the first 60 min either $1 \mathrm{~h}$ before or $2 \mathrm{~h}$ after feeding. Associated $P$-values can be found in Table 4 . For plasma propionate, insulin, BHB, and acetate, data were log-transformed for statistical analysis and back-transformed for interpretation purposes. For NEFA, data were transformed using square root for statistical analysis and back-transformed for interpretation purposes. For lactate, data were transformed using the inverse for statistical analysis and back-transformed for interpretation purposes. 


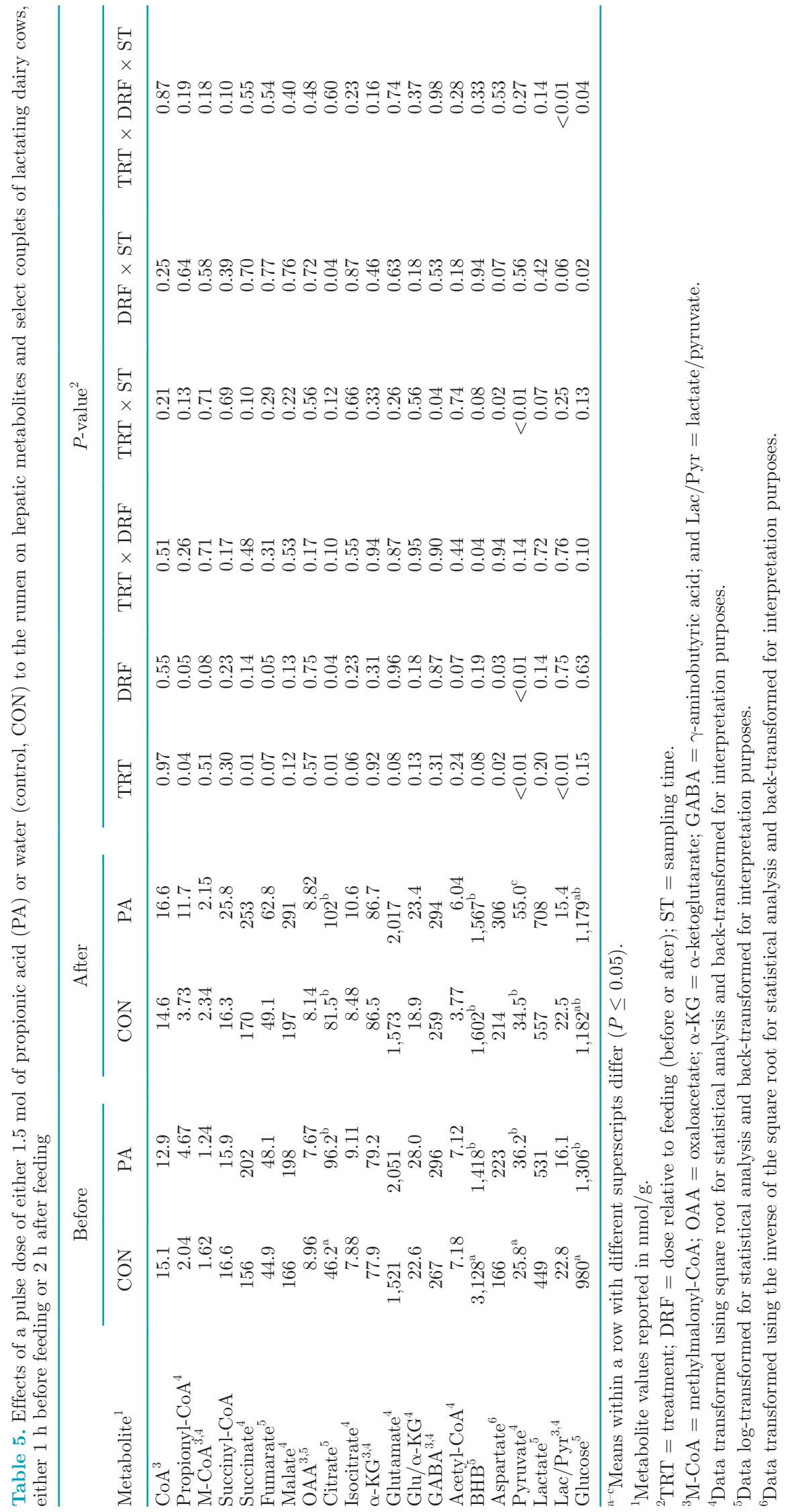


A

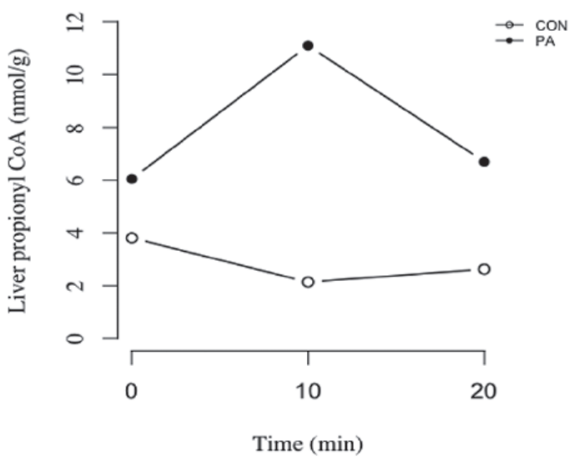

B

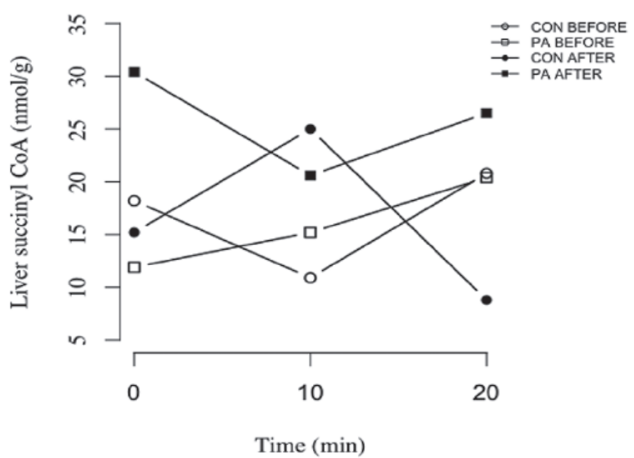

$\mathrm{C}$

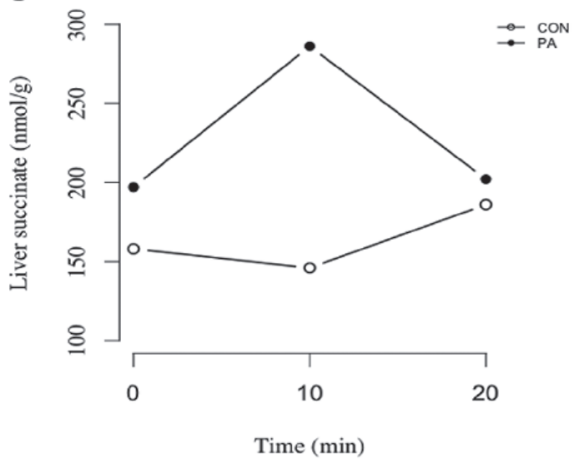

$\mathrm{D}$

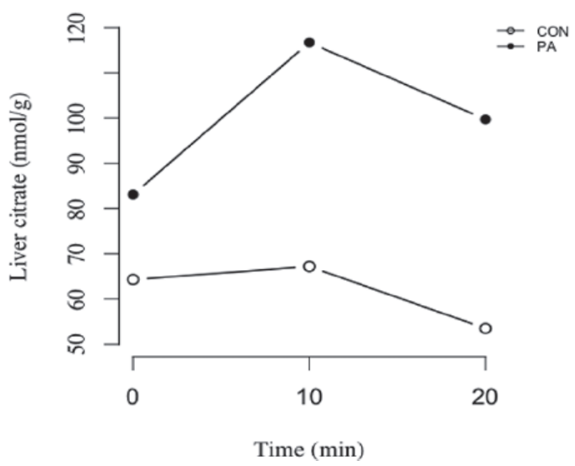

$\mathrm{E}$

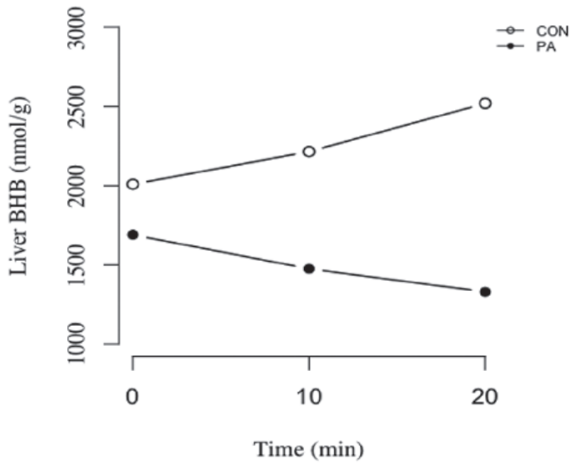

F

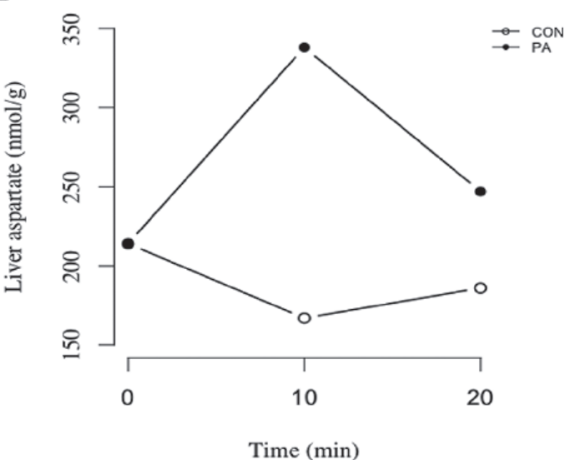

G

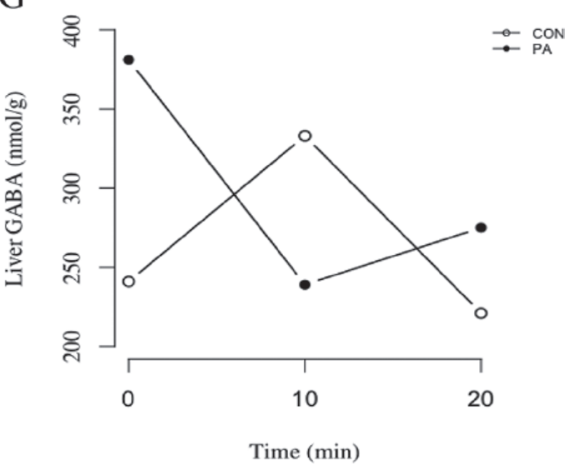

Figure 2. Effects of a pulse dose of either $1.5 \mathrm{~mol}$ of propionic acid $(\mathrm{PA})$ or water $(\mathrm{CON})$ to the rumen on hepatic concentrations of (A) propionyl-CoA, (B) succinyl-CoA, (C) succinate, (D) citrate, (E) BHB, (F) aspartate, and (G) $\gamma$-aminobutyric acid (GABA), in dairy cows in the postpartum period over the first 20 min either $1 \mathrm{~h}$ before or $2 \mathrm{~h}$ after feeding. Associated $P$-values can be found in Table 5 . For propionylCoA, succinate, and GABA, data were transformed using square root for statistical analysis and back-transformed for interpretation purposes. For citrate and BHB, data were log-transformed for statistical analysis and back-transformed for interpretation purposes. For aspartate, data were transformed using the inverse of the square root for statistical analysis and back-transformed for interpretation purposes. 
$P=0.02)$, and PA increased citrate concentration at 10 and 20 min compared with CON (pairwise tests, $P$ $=0.01$ and $P<0.01$, respectively). Additionally, mean citrate concentration was higher AF than $\mathrm{BF}$ (91.0 vs. $66.7 \mathrm{nmol} / \mathrm{g} ; P=0.04)$. The PA treatment tended to increase mean isocitrate concentration compared with CON (9.84 vs. $8.18 \mathrm{nmol} / \mathrm{g} ; P=0.06$ ) but did not affect $\alpha$-ketoglutarate concentration relative to feeding time. The PA treatment tended to increase mean hepatic glutamate concentration compared with $\mathrm{CON}$ $(2,034$ vs. $1,546 \mathrm{nmol} / \mathrm{g} ; P=0.08)$ but did not affect the ratio of glutamate to $\alpha$-ketoglutarate concentration relative to feeding time.

Hepatic acetyl-CoA concentration was not affected by PA treatment but tended to be lower AF compared with $\mathrm{BF}$ (4.84 vs. $7.15 \mathrm{nmol} / \mathrm{g} ; P=0.07$ ). The PA treatment decreased hepatic BHB concentration compared with $\mathrm{CON}$ BF (1,418 vs. $3,128 \mathrm{nmol} / \mathrm{g})$ but not
AF (1,567 vs. $1,602 \mathrm{nmol} / \mathrm{g} ; P=0.04)$, and differences between treatments increased over time (Figure 2E; $P$ $=0.08)$.

The PA treatment increased hepatic aspartate concentration compared with CON (259 vs. $188 \mathrm{nmol} / \mathrm{g} ; P$ $=0.02)$. Treatments interacted with sampling time to affect aspartate concentration (Figure 2F; interaction, $P=0.02)$, which was greater AF than $\mathrm{BF}$ (254 vs. $191 \mathrm{nmol} / \mathrm{g} ; P=0.03)$; PA increased aspartate concentration $58 \%$ (pairwise test, $P<0.01$ ) whereas $\mathrm{CON}$ decreased it $22 \%$ (pairwise test, $P=0.04$ ) at $10 \mathrm{~min}$ compared with baseline, and the concentration began to return to baseline by $20 \mathrm{~min}$. Treatments interacted with sampling time to affect GABA concentration (Figure $2 \mathrm{G} ; P=0.04$ ), with PA decreasing GABA concentration $37 \%$ at 10 min compared with baseline (pairwise test, $P=0.02$ ) and $\mathrm{CON}$ tending to increase GABA concentration $39 \%$ at 10 min compared with
A
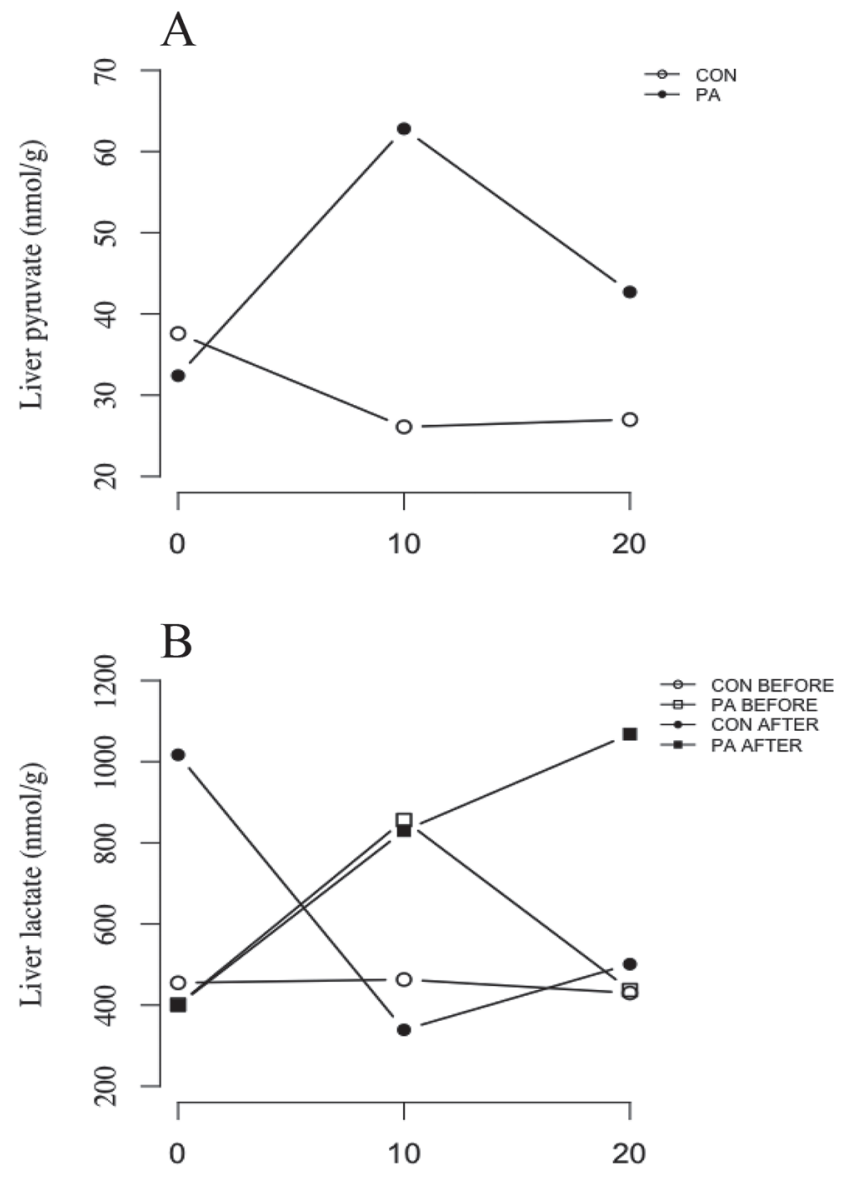

Time (min)

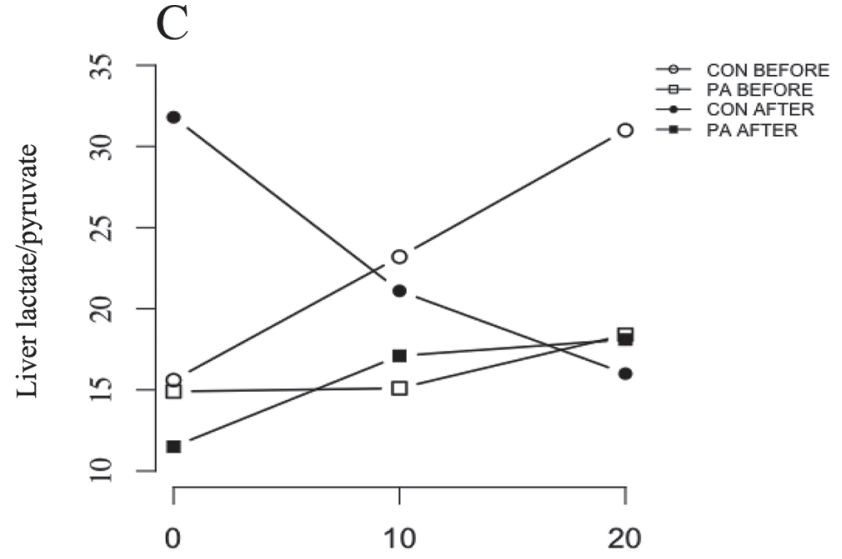

$\mathrm{D}$

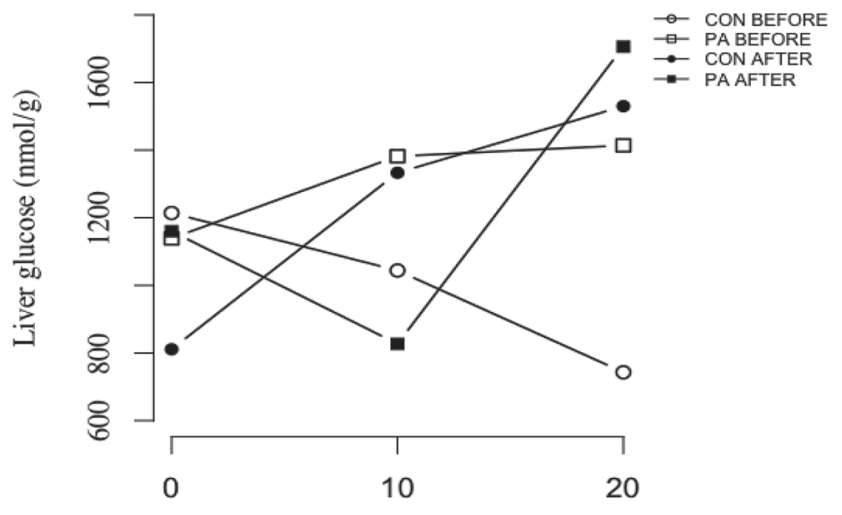

Time (min)

Figure 3. Effects of a pulse dose of $1.5 \mathrm{~mol}$ of propionic acid (PA) or water (CON) to the rumen on hepatic concentration of (A) pyruvate, (B) lactate, (C) ratio of lactate to pyruvate, and (D) glucose in dairy cows in the postpartum period over the first 20 min either before or after feeding. Associated $P$-values can be found in Table 5. For pyruvate and lactate:pyruvate ratio, data were transformed using square root for statistical analysis and back-transformed for interpretation purposes. For lactate and glucose, data were log-transformed for statistical analysis and back-transformed for interpretation purposes. 
baseline (pairwise test, $P=0.10$ ). Mean GABA concentration was greater for PA than for CON at baseline (381 vs. $241 \mathrm{nmol} / \mathrm{g}$; pairwise test, $P=0.02$ ).

The PA treatment increased hepatic pyruvate concentration compared with $\mathrm{CON}(P<0.01)$, and the increase tended to be greater AF ( 55.0 vs. $34.5 \mathrm{nmol} / \mathrm{g}$ ) than BF (36.2 vs. $25.8 \mathrm{nmol} / \mathrm{g} ; P=0.14)$. Treatments interacted with sampling time (Figure 3A; $P<0.01$ ), and $\mathrm{PA}$ increased pyruvate concentration compared with $\mathrm{CON}$ at $10 \mathrm{~min}(62.8$ vs. $26.1 \mathrm{nmol} / \mathrm{g}$; pairwise test, $P<0.01)$ and $20 \mathrm{~min}(42.7 \mathrm{vs} .27 .0 \mathrm{nmol} / \mathrm{g}$; pairwise test, $P=0.01$ ). Mean pyruvate concentration was increased AF compared with BF (44.1 vs. $30.8 \mathrm{nmol} / \mathrm{g}$; $P<0.01)$. Treatment significantly interacted with block $(P=0.05)$ in which PA increased pyruvate concentration compared with CON in multiparous cows (31.0 vs. $14.2 \mathrm{nmol} / \mathrm{g} ; P<0.01$ ) and tended to increase pyruvate concentration compared with CON in primiparous cows (61.8 vs. $51.7 \mathrm{nmol} / \mathrm{g} ; P=0.08)$. The $P A$ treatment increased hepatic lactate concentration at $10 \mathrm{~min}$ compared with CON (843 vs. $396 \mathrm{nmol} / \mathrm{g}$; pairwise test, $P=0.04)$ and differed or tended to differ compared with CON AF but not BF (Figure 3B; interaction, $P=$ 0.14). The PA treatment decreased the ratio of lactate to pyruvate $(15.8$ vs. $22.7 ; P<0.01)$, but treatment interacted with dose relative to feeding and sampling time (Figure 3C; $P<0.01$ ). The PA treatment did not affect the ratio of lactate to pyruvate compared with baseline $\mathrm{BF}$ but tended to increase it at $10 \mathrm{~min}$ (pairwise test, $P=0.06$ ) and increased it at $20 \mathrm{~min} \mathrm{AF}$ (pairwise test, $P=0.04$ ), whereas $\mathrm{CON}$ increased the ratio at 10 and $20 \mathrm{~min} \mathrm{BF}$ (pairwise tests, $P<0.05$ ) and decreased it over the sampling period AF (pairwise tests, $P \leq 0.01)$ compared with baseline. Treatment significantly interacted with block $(P=0.01)$ in which PA decreased the ratio of lactate to pyruvate compared with CON in multiparous cows (19.7 vs. $33.9 \mathrm{nmol} / \mathrm{g}$; $P<0.01)$ and did not differ compared with $\mathrm{CON}$ in primiparous cows (12.2 vs. $13.7 \mathrm{nmol} / \mathrm{g} ; P=0.42)$.

Treatments interacted with feeding status and sampling time to affect hepatic glucose concentration (Figure 3D; $P=0.04$ ). The PA treatment did not change glucose concentration over the sampling time $\mathrm{BF}$ but increased glucose between 10 and $20 \mathrm{~min}$ AF (pairwise test, $P=0.01$ ), whereas CON decreased glucose concentration $\mathrm{BF}$ at $20 \mathrm{~min}$ (pairwise test, $P=0.04$ ) and increased it AF throughout the sampling period compared with baseline (pairwise tests, $P<0.05$ ).

\section{DISCUSSION}

Propionate absorption from the rumen occurred more rapidly than expected, with effects from the pulse dose immediately measurable at the 5 -min time point. These effects were short-term and cleared within $30 \mathrm{~min}$ of administration of treatments. Furthermore, many of the hepatic reactions returned to baseline values by 20 min, which supports that diet and individual meals have acute metabolic effects that need to be considered and further explored. Observed peaks and increases in measured plasma and hepatic metabolites from a pulse dose of PA suggest possible areas of interest in which metabolism of propionate may be hindered. Because the measured hepatic metabolites follow a well-established pathway of metabolism, we are able to use the observed concentrations to identify enzymes within the pathway that may be delaying propionate metabolism, which we refer to as metabolic bottlenecks of propionate metabolism. Identification of possible metabolic bottlenecks allows us to focus future research on these specific enzymes to help us improve management strategies (nutrition, genetics, etc.) to optimize nutrient extraction and utilization during the PP period.

Therefore, a peak of plasma propionate suggests that plasma propionate is bypassing the liver despite its very efficient extraction by the liver (Baird et al., 1980; Reynolds et al., 2003). However, metabolism of propionate by other tissues is minimal (Brockman, 2005), and as such, the liver is expected to extract the vast majority of propionate in plasma, albeit requiring additional passes through the circulation. Propionyl-CoA synthetase (EC 6.2.1.17), the enzyme responsible for the activation of plasma propionate to propionyl-CoA, likely delayed the extraction of propionate from plasma. This is evidenced by the tendency toward an increase in propionyl-CoA concentration but lack of change in methylmalonyl-CoA concentration. The available CoA pool may be too large to detect minute changes caused by propionyl-CoA synthetase, which would explain why we were unable to detect treatment differences in free $\mathrm{CoA}$; as such, the availability of free CoA does not appear to be a limiting factor. However, propionyl-CoA carboxylase (EC 6.4.1.3), the enzyme responsible for converting propionyl-CoA to methylmalonyl-CoA, may also be a potential metabolic bottleneck that might explain the tendency for an increase in propionyl-CoA concentration but lack of change in methylmalonylCoA concentration.

An increase in succinate concentration suggests a possible metabolic bottleneck at succinate dehydrogenase (EC 1.3.5.1), the enzyme responsible for converting succinate to fumarate. Sun et al. (2005) hypothesized that succinate dehydrogenase may provide a feedback mechanism that maintains a balance between energy utilization and storage, given its position as part of both the TCA cycle and the electron transport chain. Therefore, a potential bottleneck at this enzyme could be a major source of interest for control and regulation 
of feed intake in accordance with the HOT (Allen et al., 2009). Also, succinate dehydrogenase is strongly inhibited by OAA (Das, 1937) and malate (Dervartanian and Veeger. 1965; Ackrell et al., 1974). However, malate and OAA are found in both the mitochondria and cytosol of cells, and malate is exported from the mitochondria to the cytosol for gluconeogenesis. Siess et al. (1977) reported that cytosol contains more than $75 \%$ of total malate concentrations found in rat liver and an even greater proportion in the presence of glucagon. We did not separate mitochondrial and cytosolic metabolites so, although neither malate nor OAA concentrations were elevated in liver tissue, they might have been elevated in the mitochondria and been diluted by the cytosolic compartment. NADH is a regulator of the TCA cycle, affecting many enzymes that use $\mathrm{NAD}^{+}$as a reducing factor, such as isocitrate dehydrogenase (EC 1.1.1.41; Williamson and Cooper, 1980) and mitochondrial malate dehydrogenase, the enzyme responsible for conversions between malate and OAA. Therefore, a tendency toward an increase in isocitrate concentration suggests reduced isocitrate dehydrogenase activity and increased $\mathrm{NADH} / \mathrm{NAD}^{+}$. A mitochondrial increase of $\mathrm{NADH} / \mathrm{NAD}^{+}$may cause malate to be shunted toward gluconeogenesis, which aligns with Zhang et al. (2015), who reported a tendency for a greater flux of OAA to pyruvate and glucose in cows receiving propionate infusions. Additionally, mitochondrial malate may convert to fumarate or decrease the rate of fumarate conversion to malate when accumulated. Therefore, a tendency for fumarate concentration to increase with PA further supports that an accumulation of mitochondrial malate may have occurred.

The spike in plasma insulin concentration was likely a result of an increase in plasma propionate concentration (Horino et al., 1968; Bines and Hart, 1984) because it coincides with the peak in plasma propionate concentration, whereas plasma glucose concentration did not peak until later. Furthermore, the increase in plasma insulin concentration likely caused the decrease in plasma NEFA concentration observed BF. Whereas a reduction in plasma NEFA concentration would be expected to decrease hepatic concentration of acetylCoA (Piantoni et al., 2015), acetyl-CoA was unaffected by treatment. This was likely because PA decreased hepatic BHB concentration. Citrate concentration, however, increased $108 \%$ with PA compared with control $\mathrm{BF}$ and tended to increase over time by $\mathrm{PA}$ compared with CON both BF and AF. Generally, the availability of acetyl-CoA and OAA as substrates for citrate synthase (EC 2.3.3.1), the enzyme responsible for the formation of citrate, is low, which can affect citrate formation (Williamson and Cooper, 1980). In addition, the conversion between citrate and isocitrate is a reversible reaction, and as such, the tendency for an increase in isocitrate concentration could contribute to the accumulation of citrate. However, no spikes of isocitrate concentration were observed, and the accumulated isocitrate concentration would most likely be derived from citrate. Therefore, the increase in citrate concentration is likely from the conversion of acetylCoA and OAA to citrate through citrate synthase.

Circulating plasma NEFA concentration was lower AF compared with BF, as expected, and did not decrease with PA AF, as observed $\mathrm{BF}$, despite an increase in plasma insulin concentration AF. Furthermore, the overall decrease in plasma NEFA concentration $\mathrm{AF}$ compared with $\mathrm{BF}$ is likely responsible for the tendency for hepatic acetyl-CoA concentration to decrease AF compared with $\mathrm{BF}$, which is in agreement with previous research (Piantoni et al., 2015). Plasma and hepatic $\mathrm{BHB}$ concentration decreased both $\mathrm{BF}$ and $\mathrm{AF}$; however, this decrease is not as evident $\mathrm{AF}$ as $\mathrm{BF}$, consistent with the decreased plasma NEFA concentration AF.

The increase in pyruvate and lactate concentrations suggests one or a combination of the following: (1) excess carbons and reducing equivalents are contributing to gluconeogenesis from transfer of mitochondrial malate to the cytosol; (2) another metabolic bottleneck associated with pyruvate may be present; (3) the system is high in cytosolic $\mathrm{NADH} / \mathrm{NAD}^{+}$; or (4) the system is likely trying to regenerate $\mathrm{NAD}^{+}$from $\mathrm{NADH}$ $+\mathrm{H}^{+}$. High NADH levels, along with other inhibitors, can reduce the conversion of pyruvate to acetyl-CoA and may shunt carbons toward gluconeogenesis. Along with an excess of carbon supplied by propionyl-CoA metabolism in the mitochondria, the accumulation of pyruvate may also signify a metabolic bottleneck. However, multiple enzymes are associated with pyruvate metabolism and determining which enzyme or enzymes may be contributing to the increase in pyruvate is not possible from our experimental results. The lactate/ pyruvate couplet, which has been used to estimate the ratio of cytosolic $\mathrm{NAD}^{+} / \mathrm{NADH}$ (Williamson et al., 1967), decreased with PA compared with CON in multiparous cows, supporting the assumption of a high ratio of cytosolic $\mathrm{NADH} / \mathrm{NAD}^{+}$. Although the ratio increases $\mathrm{BF}$ with $\mathrm{PA}$ compared with the baseline over the sampling period, these increases are not as great as with CON, suggesting a larger pool of cytosolic NADH with PA treatment, likely resulting from exportation of mitochondrial malate to the cytosol. Furthermore, the increase in lactate concentration noted with PA treatment is likely directly related to the increase in pyruvate concentration because pyruvate can be converted to lactate, a reaction that regenerates $\mathrm{NAD}^{+}$in the process. The increase in plasma lactate concentration may be the result of the increased hepatic lactate con- 
centration being released into circulation or a decrease in hepatic uptake of lactate (Baird et al., 1980).

Glutamate, a major excitatory neurotransmitter, has been reported to excite abdominal vagal afferents in rats (Tsurugizawa et al., 2009). Conversely, glutamate can convert to GABA, an inhibitory neurotransmitter that may also play a role in signaling satiety through the vagus hepatic nerve. The hepatic concentration of GABA in humans is $252 \mathrm{nmol} / \mathrm{g}$, and an experiment with rats observed almost a doubling of hepatic GABA concentration within $4 \mathrm{~h}$ following a $70 \%$ partial hepatectomy (Minuk, 1992). However, GABA concentration decreased with PA treatment, whereas glutamate concentration had a tendency to increase, suggesting that glutamate was not converting to GABA. Firing rate is decreased when energy status increases, inhibiting feeding (Friedman, 1997), and previous studies have reported hypophagic effects of propionate (Allen, 2000; Gualdrón-Duarte and Allen, 2017; Maldini and Allen, 2018). Therefore, we would expect to see the opposite patterns of glutamate and GABA concentrations if these neurotransmitters were responsible for regulating feeding behavior through the HOT. Aspartate has been reported to be an excitatory neurotransmitter as well (Dingledine and McBain, 1999); however, aspartate concentration also increased, suggesting that it is not a likely neurotransmitter candidate for the HOT.

For those metabolites affected by dose relative to feeding main effects (BF vs. AF), the concentrations of respective hepatic metabolites were generally higher $\mathrm{AF}$ than $\mathrm{BF}$, as hypothesized, suggesting that some metabolic bottlenecks may be more apparent AF, such as propionyl-CoA synthetase. Recently consumed feed in the rumen would cause greater propionate production, particularly if feeds consumed were high in starch. As such, enzymes and cofactors associated with propionate metabolism may be reaching their saturation and depletion limits, respectively, as a result of these pre-existing higher levels of metabolites before dosing.

Frequently, DMI is evaluated and reported daily. However, daily DMI intake is a function of: (1) the number of meals eaten per day, (2) the amount of feed eaten per meal, (3) the length of each meal, and (4) the length of time between meals (Allen, 2014). Previous research has shown that propionate decreases meal frequency and meal size (Maldini and Allen, 2018) and that hepatic vagotomy diminishes the hypophagic effects of propionate in sheep (Anil and Forbes, 1988). As such, understanding the short-term metabolism of propionate within a meal may help with describing daily DMI and feeding behavior. By understanding mechanistically what is occurring within the meal, future studies and research can be directed toward maximizing daily DMI through manipulation of the aforementioned parts. This is especially important during the first few weeks postpartum, when appetite is suppressed.

We propose that elevated $\mathrm{NADH} / \mathrm{NAD}^{+}$during the postpartum period likely created bottlenecks for certain reactions within the TCA cycle, slowing TCA activity and ATP production despite anaplerosis from propionate, and shunting carbons and reducing equivalents to the cytosol for gluconeogenesis. As such, these metabolic bottlenecks likely delay satiety within a meal, increasing meal size but extending intermeal interval. This study shows that metabolism is occurring very quickly. We hope it stimulates further research on metabolism focused on a short timescale.

\section{CONCLUSIONS}

This study demonstrated the following: (1) absorption of propionate from the rumen into the bloodstream, and subsequent extraction by the liver, is very rapid; (2) the metabolic effects of propionate are rapid, occurring within the time frame of a meal; and (3) metabolic bottlenecks for propionate metabolism occur that might affect feeding behavior. Specifically, we suggest potential metabolic bottlenecks of propionate metabolism at propionyl-CoA synthetase and succinate dehydrogenase. Additionally, as expected, feeding status can affect metabolite concentrations and response to propionate with metabolite concentrations generally higher after than before feeding. Understanding the metabolic mechanisms that contribute to feeding behavior builds the foundation for developing methods to alter energy intake and partitioning in lactating dairy cows, ultimately increasing health and milk production. Future research is required to understand how different fuels affect liver metabolism, oxidation, and DMI within the time frame of a meal for dairy cows in the PP period.

\section{ACKNOWLEDGMENTS}

We gratefully acknowledge financial support for this project from the Michigan Alliance for Animal Agriculture (MSU AgBio Research, Michigan State University). We also thank R. J. Tempelman for statistical advice, A. D. Jones, S. Smith, L. Chen, and A. Schilmiller for mass spectrometry training and advice, and D. G. Main, L. G. Duarte, R. Albornoz, G. Maldini, R. Yair, M. Bowers, and R. West (all from Michigan State University), as well as the staff of the Michigan State University Dairy Cattle Field Laboratory (East Lansing) and Michigan State University Mass Spectrometry and Metabolomics Core (East Lansing) for their assistance in this experiment, S. Donkin (Purdue University, West Lafayette, IN) for providing us with 
biopsy tools, and Kemin Animal Nutrition and Health (Des Moines, IA) for supplying propionic acid.

\section{REFERENCES}

Ackrell, B. A., E. B. Kearney, and M. Mayr. 1974. Role of oxalacetate in the regulation of mammalian succinate dehydrogenase. J. Biol. Chem. 249:2021-2027.

Aiello, R. J., L. E. Armentano, S. J. Bertics, and A. T. Murphy. 1989. Volatile fatty acid uptake and propionate metabolism in ruminant hepatocytes. J. Dairy Sci. 72:942-949. https://doi.org/10.3168/jds .S0022-0302(89)79187-6.

Allen, M. S. 2000. Effects of diet on short-term regulation of feed intake by lactating dairy cattle. J. Dairy Sci. 83:1598-1624. https:// doi.org/10.3168/jds.S0022-0302(00)75030-2.

Allen, M. S. 2014. Drives and limits to feed intake in ruminants. Anim. Prod. Sci. 54:1513-1524. https://doi.org/10.1071/AN14478.

Allen, M. S., B. J. Bradford, and M. Oba. 2009. Board-invited review: The hepatic oxidation theory of the control of feed intake and its application to ruminants. J. Anim. Sci. 87:3317-3334. https://doi .org/10.2527/jas.2009-1779.

Anil, M. H., and J. M. Forbes. 1988. The roles of hepatic nerves in the reduction of food intake as a consequence of intraportal sodium propionate administration in sheep. Q. J. Exp. Physiol. 73:539 546. https://doi.org/10.1113/expphysiol.1988.sp003174.

Baird, G. D., M. A. Lomax, H. W. Symonds, and S. R. Shaw. 1980 Net hepatic and splanchnic metabolism of lactate, pyruvate and propionate in dairy cows in vivo in relation to lactation and nutrient supply. Biochem. J. 186:47-57. https://doi.org/10.1042/ bj1860047.

Bines, J. A., and I. C. Hart. 1984. The response of plasma insulin and other hormones to intraruminal infusion of VFA mixtures in cattle. Can. J. Anim. Sci. 64:304-305. https://doi.org/10.4141/ cjas84-272.

Bradford, B. J., and M. S. Allen. 2005. Phlorizin administration increases hepatic gluconeogenic enzyme mRNA abundance but not feed intake in late-lactation dairy cows. J. Nutr. 135:2206-2211. https://doi.org/10.1093/jn/135.9.2206.

Brockman, R. P. 2005. Glucose and short-chain fatty acid metabolism. Pages 291-310 in Quantitative Aspects of Ruminant Digestion and Metabolism. CAB International, Wallingford, UK.

Das, N. B. 1937. Studies on the inhibition of the succinic and lacticmalic dehydrogenases. Biochem. J. 31:1124-1130.

Dervartanian, D. V., and C. Veeger. 1965. Studies on succinate dehydrogenase. II. On the nature of the reaction of competitive inhibitors and substrates with succinate dehydrogenase. Biochim. Biophys. Acta. Enzymol. Biol. Oxid. 105:424-436. https://doi.org/10 .1016/S0926-6593(65)80228-4.

Dingledine, R., and C. J. McBain. 1999. Glutamate and aspartate are the major excitatory transmitters in the brain. Pages 267-289 in Basic Neurochemistry: Molecular, Cellular and Medical Aspects. 6th ed. G. J. Siegel, B. W. Agranoff, R. W. Albers, S. K. Fisher, and M. D. Uhler, ed. Lippincott Williams \& Wilkins, Philadelphia, PA.

Donkin, S. S., and L. E. Armentano. 1995. Insulin and glucagon regulation of gluconeogenesis in preruminating and ruminating bovine. J. Anim. Sci. 73:546-551. https://doi.org/10.2527/1995.732546x.

Friedman, M. I. 1997. An energy sensor for control of energy intake. Proc. Nutr. Soc. 56:41-50. https://doi.org/10.1079/PNS19970008.

Gotoh, K., Y. Nakajima, G. Tajima, Y. Hotta, T. Kataoka, Y. Kawade, N. Sugiyama, T. Ito, K. Kimura, and Y. Maeda. 2015. Assay for methylmalonyl coenzyme A mutase activity based on determination of succinyl coenzyme A by ultrahigh-performance liquid chromatography tandem mass spectrometry. Anal. Bioanal. Chem. 407:5281-5286. https://doi.org/10.1007/s00216-015-8753-8.

Gualdrón-Duarte, L. B., and M. S. Allen. 2017. Increased anaplerosis of the tricarboxylic acid cycle decreased meal size and energy intake of cows in the postpartum period. J. Dairy Sci. 100:44254434. https://doi.org/10.3168/jds.2016-12104.

Horino, M., L. J. Machlin, F. Hertelendy, and D. M. Kipnis. 1968. Effect of short-chain fatty acids on plasma insulin in ruminant and nonruminant species. Endocrinology 83:118-128. https://doi.org/ 10.1210/endo-83-1-118.

Kennedy, K. M., and M. S. Allen. 2017. Effects of a pulse dose of propionate on metabolic response in lactating dairy cows during the postpartum period. J. Dairy Sci. 100(E-Suppl. 2):112. (Abstr.)

Kind, T., G. Wohlgemuth, D. Y. Lee, Y. Lu, M. Palazoglu, S. Shahbaz, and O. Fiehn. 2009. FiehnLib: Mass spectral and retention index libraries for metabolomics based on quadrupole and timeof-flight gas chromatography/mass spectrometry. Anal. Chem. 81:10038-10048. https://doi.org/10.1021/ac9019522.

Maldini, G., and M. S. Allen. 2018. Temporal effects of ruminal propionic acid infusion on feeding behavior of Holstein cows in the postpartum period. J. Dairy Sci. 101:3077-3084. https://doi.org/ $10.3168 /$ jds.2017-13857.

Minuk, G. Y. 1992. GABA and the liver: The first 40 years. Pages 143-154 in GABA Outside the CNS. S. L. Erdö, ed. Springer, Berlin, Germany.

Piantoni, P., C. M. Ylioja, and M. S. Allen. 2015. Feed intake is related to changes in plasma nonesterified fatty acid concentration and hepatic acetyl CoA content following feeding in lactating dairy cows. J. Dairy Sci. 98:6839-6847. https://doi.org/10.3168/jds.2014 -9085 .

Reynolds, C. K., P. C. Aikman, B. Lupoli, D. J. Humphries, and D. E. Beever. 2003. Splanchnic metabolism of dairy cows during the transition from late gestation through early lactation. J. Dairy Sci. 86:1201-1217. https://doi.org/10.3168/jds.S0022-0302(03)73704 -7 .

Siess, E. A., D. G. Brocks, H. K. Lattke, and O. H. Wieland. 1977. Effect of glucagon on metabolite compartmentation in isolated rat liver cells during gluconeogenesis from lactate. Biochem. J. 166:225-235.

Sun, F., X. Huo, Y. Zhai, A. Wang, J. Xu, D. Su, M. Bartlam, and Z. Rao. 2005. Crystal structure of mitochondrial respiratory membrane protein complex II. Cell 121:1043-1057. https://doi.org/10 .1016 /j.cell.2005.05.025.

Tsurugizawa, T., A. Uematsu, E. Nakamura, M. Hasumura, M. Hirota, T. Kondoh, H. Uneyama, and K. Torii. 2009. Mechanisms of neural response to gastrointestinal nutritive stimuli: The gut-brain axis. Gastroenterology 137:262-273. https://doi.org/10.1053/j .gastro.2009.02.057.

Williamson, D. H., P. Lund, and H. A. Krebs. 1967. The redox state of free nicotinamide-adenine dinucleotide in the cytoplasm and mitochondria of rat liver. Biochem. J. 103:514-527.

Williamson, J. R., and R. H. Cooper. 1980. Regulation of the citric acid cycle in mammalian systems. FEBS Lett. 117:K73-K85. https://doi.org/10.1016/0014-5793(80)80572-2.

Zhang, Q., S. L. Koser, B. J. Bequette, and S. S. Donkin. 2015. Effect of propionate on mRNA expression of key genes for gluconeogenesis in liver of dairy cattle. J. Dairy Sci. 98:8698-8709. https://doi .org/10.3168/jds.2015-9590. 